\title{
Comparison of Flipped Classroom and Conceptual Map on Students' Deliberate Practice Study Approach
}

\author{
Amin Haghgoo ${ }^{1}$, Mahmood Karimy (iD ${ }^{1}$, Meysam Rahmani Katigari ${ }^{2,{ }^{*}}$, Mohadese Bolhasani ${ }^{3}$, Ghazal \\ Afsheh $^{3}$ and Behnam Jafari ${ }^{4}$ \\ ${ }^{1}$ Social Determinants of Health Research Center, Saveh University of Medical Sciences, Saveh, Iran \\ ${ }^{2}$ School of Allied Medical Sciences, Tehran University of Medical Sciences, Tehran, Iran \\ ${ }^{3}$ Student Research Committee, Saveh University of Medical Sciences, Saveh, Iran \\ ${ }^{4}$ Student Research Committee, Yasuj University of Medical Sciences, Yasuj, Iran \\ "Corresponding author: Ph.D. Candidate of Health Information Management, School of Allied Medical Sciences, Tehran University of Medical Sciences, Tehran, Iran. Tel: \\ +98-9151901855, Email: m-rahmanik@razi.tums.ac.ir
}

Received 2018 October 11; Revised 2019 January 10; Accepted 2019 January 14.

\begin{abstract}
Background: The most important goal of educational systems is to increase learners' learning and improve their quality, especially in the field of health due to direct relation with people's lives. Use of active teaching methods such as flipped classrooms and conceptual map are suggested for increasing communication skills, participation, creativity, and critical thinking of students. On the other hand, deliberate practice is an active study method that leads to informed learning and deep understanding of the content. Objectives: In order to cultivate and develop learning skill, the present study is aimed at comparing the effect of teaching through flipped classroom and conceptual map on deliberate practice study approach in students of operating room technology and anesthesiology in 2017.

Methods: It was a quasi-experimental study with the aim of comparing flipped classroom and conceptual map on deliberate practice study approach of undergraduate students of operating room technology and anesthesiology in the Faculty of Nursing and Midwifery in Saveh University of Medical Sciences. In this method, sampling was not used and all the population entered the study. Sixty students randomly divided into two groups of flipped classroom and conceptual map. Duvivier deliberate practice study approach questionnaire was used to collect data. Data were analyzed using descriptive statistics and inferential statistics ( $t$-test, paired $t$-test) by SPSS 21 software.

Results: There was a significant difference between the pre-test and post-test means of the students in two groups (P > 0.001). Comparison of pre-test and post-test means of deliberate practice study approach and its components between the flipped classroom and conceptual map showed a significant difference $(\mathrm{P}<0.001)$. Also, the greatest difference between flipped classroom and conceptual map is related to the planning $(\mathrm{P}<0.001)$ and study style or self-reflective $(\mathrm{P}=0.004)$ variables.

Conclusions: Considering that conceptual mapping and flipped classrooms influenced students' deliberate practice study approach, it is possible to plan for the use of these two methods in medical and paramedical students' education system.
\end{abstract}

Keywords: Conceptual Map, Deliberate Practice Study Approach, Flipped Classroom, Education Methods.

\section{Background}

The most important goal of educational systems is to increase learners' learning and improve their quality. Such an idea, especially in the field of health, is very important because of the direct relationship with people's lives (1). In recent decades, scientists and scholars have switched from teaching to an emphasis on student learning. This orientation is often referred to as axial learning. This approach focuses on the processes used for learning $(2,3)$.

The learning and study approaches can affect the overall satisfaction of the course. This overall satisfaction of the course can affect students' academic status $(4,5)$. In this regard, Ericsson applied the deliberate practice study approach (6). This active study style focuses on gaining a deep understanding rather than maintaining parrot-wise learning (7). In their research, Moulaert et al. reported that facets of deliberate practice such as planning, studying style, and motivation have a positive relationship with academic achievement. Students with higher academic qualifications have higher deliberate practice levels than students with lower academic achievement (7). Also, the results of another study showed that using deliberate practice in nursing students is very effective in their profes- 
sional activities (8).

Inactive teaching methods, due to the practiceoriented nature of medical sciences, reduces clinical practice, clinical decision-making, critical thinking, problem-solving, and academic achievement in these students (9). Through active methods, students are engaged in finding information and solving problems and their creativity and critical thinking skills (10). Research findings showed that $92 \%$ of nursing students preferred active and modern teaching methods compared to traditional ways (11) and using a single method is boring (12). So, the literature review tells us that the gap between nursing education and real practice can be eliminated by student engagement and using active learning techniques (13).

Two of the most important methods emphasized in various papers, especially in the field of medicine, are the flipped classroom and conceptual map methods (1315). Use of flipped classroom and conceptual map are suggested for increasing communication skills, participation, creativity, critical thinking of students and eliminating the problem of a large volume of medical science lessons and time constraints in classes (16).

The flipped classroom is considered a Blended Learning model that incorporates various teaching approaches such as collaborative learning of the class, lab experimental activities, and teaching through online videos or individual training. In other words, the role of the university and the home will change $(17,18)$. The goal of the flipped classroom is self-directed Learning. In this method, educational content is provided for students before the class to be studied and practiced at home and the class time is spent on student-centered learning activities such as learning to solve problems or exploratory-based learning (19).

Another innovative method of teaching-learning used in education, developmental evaluation, final evaluation, and educational planning is conceptual map, derived from the meaningful learning theory of Ausubel $(20,21)$. The conceptual map sets out a set of concepts and meanings in a systematic framework and a hierarchy order consistent with the structure and learning of the human brain by providing a logical link between them at different levels (21). Various studies have examined the effectiveness of this method on learning of nurses' skills (22), creativity, and self-efficacy (23).

\section{Objectives}

Since the study on the comparison of teaching using flipped classroom and conceptual map was not conducted in Iran, this study was conducted with the aim of "comparing teaching effectiveness of flipped classroom method and conceptual map on undergraduate students of operating room technology and anesthesiology".

\section{Methods}

The study was carried out at the Saveh University of Medical Sciences, Iran in 2017. A quasi-experimental study was used with the aim of comparing teaching effectiveness through flipped classroom and conceptual mapping on undergraduate students of operating room technology and anesthesiology. Due to the uniformity of the content of the lessons mentioned in both disciplines, as well as the same work environment and vocabulary, they were selected for intervention. Also, the medical terminology course was chosen for this study due to the nature of boredom and volatility. The statistical population of the study consisted of all students of the faculty of nursing and midwifery in the second semester of the academic year of 2017 who had to spend the course of medical terminology. In this method, sampling was not used and all the population entered the study. Sixty undergraduate students studying from January to June 2017 in the second semester randomly divided into two groups of flipped classroom and conceptual map. For this purpose, the individuals' names were entered Excel software and random function was used for determining the order and separation of the individuals. The criteria for entering the study included the selection of medical terminology course for the first time in Jun 2017 and students who had more than four absences were excluded from the study according to the school's educational rules. All individuals in the sample were present at the end of the study.

The ethics committee of research approved the study and ethics code was allocated accordingly. In addition, written informed consent was obtained from all participants.

Data were collected as pre-test and post-test. Duvivier deliberate practice study approach questionnaire was used to collect information. The questionnaire consists of two parts: demographic information section and a second section, including questions related to deliberate action. It had 26 items that comprise four components: planning (items 1 to 7), concentration/dedication (items 8 to 11), repetition/revision (items 12 to 15), study style/self reflection (items 16 to 25). For each item, a 5-point Likert scale was used (1 (by no means) to 5 (always)). The minimum possible score was 25 and the maximum possible score was 125 for each person.

The face and content validity of this questionnaire were confirmed in the study of Duvivier et al by four medical education experts. Translation and back translation 
method was used for switch to Persian language and cultural adaptation of the questionnaire. In this way, the original questionnaire was carefully translated by the researchers into Persian and translated into English by two English language experts. To determine the face and content validity of the questionnaire, 10 nursing and midwifery teachers and educators were given and, based on their feedback, minor changes were made to the words and phrases. Also, the validity of this questionnaire has also been confirmed by Nili and Abdi (24).

The reliability of the main questionnaire was determined by its Cronbach alpha, which was 0.76 in the planning section, 0.57 in concentration/dedication section, 0.67 in repetition/revision section and 0.73 in the study style/self-reflection. In the present study, Cronbach's alpha coefficient was used to measure reliability, which was $0.86,0.76,0.82,0.90$ for the sectors in questions and 0.84 in total. The content of intervention in both groups included topics related to medical terminology based on the approved headings of the Ministry of Health and Medical Education. Intervention in both groups was performed in 5 sessions of 90 minutes.

In the conceptual map group (Figure 1), the first step (introduction of content) included learners' acquaintance with conceptual maps, conceptual map features, how to draw maps and examples of it. Then, the learners developed a conceptual map individually and with the help of the teacher and the evaluation of the conceptual maps was done by the teacher for categorizing students. At the end of the first step, students were divided into six groups of five to complete their assignments. At the next step (contribution of the students to the conceptual map), students prepared their conceptual maps at home as assignments. The implementation process in another step (examination), included collective presentation, student maps collection, assessment of previous learning based on conceptual maps, returning previous maps with oral and written feedback, and teaching new subjects.

Also, the intervention in the flipped classroom was carried out in three steps (Figure 2). In the first phase (introduction of content), the flipped classroom method was introduced to the students and the lesson plan was explained to them. In the second step (contribution of the students in the flipped classroom), the content of the course was recorded in lectures and recorded sessions were available to the students on the Web. Then students heard and studied content taught by the teacher at home. There were also resources available to these students to solve the problem. In the third step (examination), the teacher held a virtual web-based each week for questioning and answering to the students. Then the teacher reviewed the contents of the previous sessions in the classroom after attending the classroom for 15 minutes and within 60 minutes, the other students solved the classroom exercises in groups. During the classroom, the student continually observed students' activities and assessed and provided feedback to the students. During the third phase and at the end of each session, 15 minutes of developmental evaluation of students were done by asking questions from the lessons provided. It should be noted that several people were used to prevent fraud in all stages.

Finally, the data were analyzed using SPSS 21 software and presented in descriptive and inferential statistics ( $t$ test and paired $t$-test).

\section{Results}

The demographic findings of the research showed, in terms of age, the flipped classroom had a mean and standard deviation (SD) of $19.45 \pm 1.23$, and the conceptual map group had a mean \pm SD of $19.65 \pm 1.62$. The mean \pm SD of student grade point average in the flipped classroom was $16.01 \pm 1.01$ and in the conceptual map was $16.12 \pm 1.15$.

In the flipped classroom, 8 (27\%) were male and 22 (73\%) female. On the other hand, in the conceptual map group, $6(20 \%)$ were male and 24 (80\%) female (Table 1$)$.

\begin{tabular}{lccc}
\hline Table 1. Comparison of Two Groups by Demographic Information ${ }^{\mathrm{a}}$ \\
\hline Variable & \multicolumn{3}{c}{ Group } \\
\cline { 2 - 4 } & $\begin{array}{c}\text { Flipped } \\
\text { Classroom }\end{array}$ & $\begin{array}{c}\text { Conceptual } \\
\text { Map }\end{array}$ & Total \\
\hline Age & $19.30 \pm 1.17$ & $19.63 \pm 1.24$ & $19.46 \pm 1.20$ \\
$\begin{array}{l}\text { Grade point } \\
\text { average }\end{array}$ & $16.08 \pm 0.91$ & $16.03 \pm 1.11$ & $16.05 \pm 1.01$ \\
Sex & $8(27)$ & $6(20)$ & $14(24)$ \\
\multicolumn{1}{c}{ Male } & $22(73)$ & $24(80)$ & $46(76)$ \\
\hline \multicolumn{1}{c}{ Female } & & & \\
\hline
\end{tabular}

${ }^{\mathrm{a}}$ Values are expressed as mean $\pm \mathrm{SD}$ and No. (\%).

According to Table 2, the comparison of the pre-test and post-test means showed that all items in deliberate practice in flipped classroom were significant. The greatest difference was related to the planning variable (Dif $=+$ 7.70), which was the most improvement after the class in this variable. There was a significant difference between the pre-test and post-test means of students' deliberate practice in the flipped classroom $(\mathrm{P}<0.001)$ (Table 2$)$.

Also, According to Table 3, the comparison of the pretest and post-test means showed that all items in deliberate practice in conceptual map were significant. The greatest difference was related to the planning variable (Dif $=+$ 10.83), which was the most improvement after the class in 


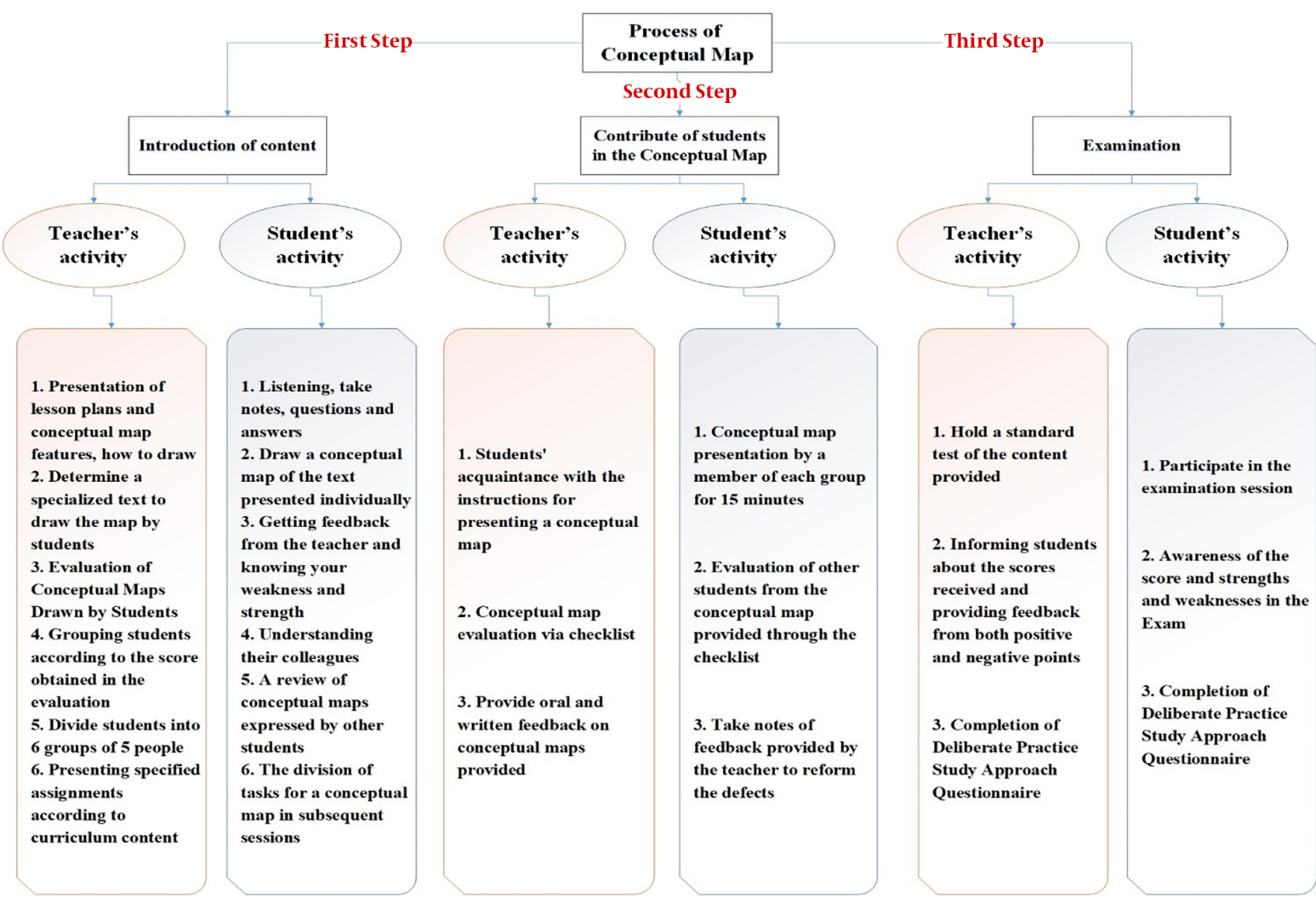

Figure 1. The training process with concept mapping

Table 2. Comparison of the Pre-Test and Post-Test Means of Deliberate Practice and its Components in the Flipped Classroom

\begin{tabular}{lcccccc}
\hline Variable & Pre-Test $^{\mathbf{a}}$ & Post-Test $^{\mathbf{a}}$ & No. & Difference Mean & $\mathbf{T}^{\mathbf{b}}$ & P Value $^{\mathbf{b}}$ \\
\hline Deliberate practice components & & & & & & \\
$\quad$ Planning & $19.46 \pm 4.22$ & $27.16 \pm 3.08$ & 30 & +7.70 & -18.4 & 0.001 \\
$\quad$ Concentration/dedication & $11.86 \pm 2.35$ & $17.5 \pm 1.08$ & 30 & +5.63 & -14.4 & 0.001 \\
$\quad$ Repetition/revision & $11.2 \pm 2.42$ & $16.36 \pm 1.15$ & 30 & +5.16 & -11.68 & 0.001 \\
$\quad$ Study style/self-reflective & $29.23 \pm 7.13$ & $36.46 \pm 2.93$ & 30 & +7.23 & -8.02 & 0.001 \\
Deliberate practice & $71.76 \pm 11.32$ & $97.5 \pm 6.25$ & 30 & +25.74 & -19.61 & 0.001 \\
\hline
\end{tabular}

${ }^{\mathrm{a}}$ Values are expressed as mean $\pm \mathrm{SD}$.

${ }^{\mathrm{b}}$ Paired $t$-test.

this variable. There was a significant difference between the pre-test and post-test means of students' deliberate practice in the conceptual map group $(\mathrm{P}<0.001)$ (Table 3$)$.

Generally, the comparison of pre-test and post-test means of scores related to deliberate practice and its components showed a significant difference between flipped classroom and conceptual map $(\mathrm{P}<0.001)$ (Table 4). The greatest difference between flipped classroom and conceptual map is related to the planning $(\mathrm{P}<0.001)$ and study style or self-reflective $(\mathrm{P}=0.004)$ variables. There was no significant relationship between other variables.

\section{Discussion}

Based on the obtained results, it was found that both methods of teaching had a positive effect on students' deliberate practice study approach. None of these studies have reviewed and compared these two approaches to 


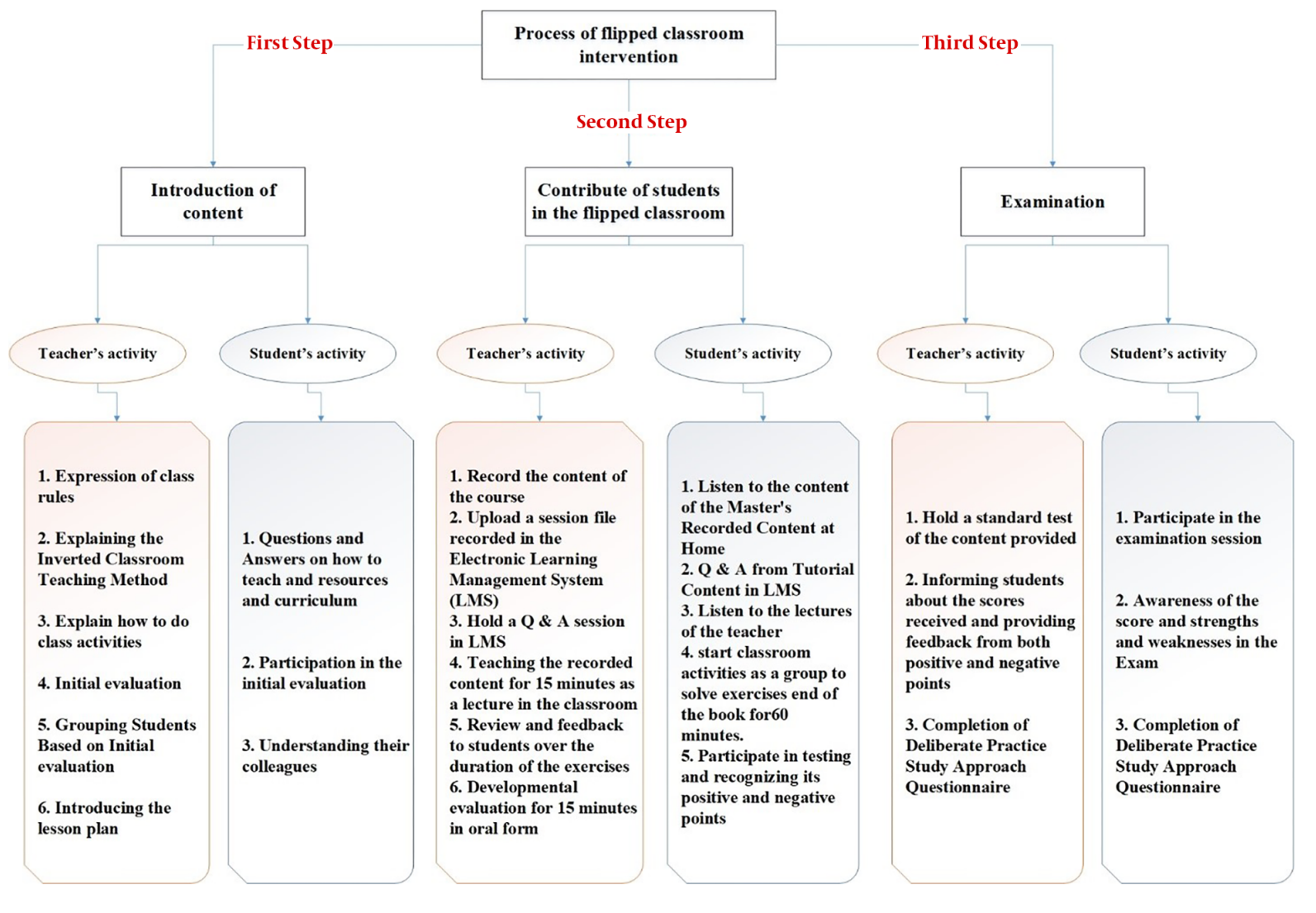

Figure 2. The training process with flipped classroom

\begin{tabular}{|c|c|c|c|c|c|c|}
\hline Variable & Pre-Test $^{a}$ & Post-Test $^{\mathbf{a}}$ & No. & Difference Mean & $\mathbf{T}^{\mathbf{b}}$ & PValue $^{\text {b }}$ \\
\hline \multicolumn{7}{|l|}{ Deliberate practice components } \\
\hline Planning & $17.7 \pm 2.76$ & $28.53 \pm 1.52$ & 30 & +10.83 & -27.18 & 0.001 \\
\hline Concentration dedication & $12.46 \pm 1.1$ & $19.23 \pm 2.93$ & 30 & +6.76 & -13.17 & 0.001 \\
\hline Repetition/revision & $12.46 \pm 2.08$ & $19.13 \pm 0.62$ & 30 & +6.66 & -18.05 & 0.001 \\
\hline Study style/self-reflective & $30.33 \pm 3.99$ & $40.9 \pm 1.64$ & 30 & +10.56 & -16.86 & 0.001 \\
\hline Deliberate practice & $72.96 \pm 7.13$ & $107.8 \pm 3.32$ & 30 & +34.84 & -31.98 & 0.001 \\
\hline
\end{tabular}

${ }^{\mathrm{a}}$ Values are expressed as mean $\pm \mathrm{SD}$.

${ }^{\mathrm{b}}$ Paired $t$-test.

the deliberate practice study approach; however, several studies were conducted on the impact of these two methods in comparison to other educational methods such as Kaddoura et al. They investigated the impact of the concept map on the critical thinking of nursing students in two pathophysiology and pharmacology lessons and concluded that the trained group had a better improvement in the concept mapping method than control group students that trained by traditional conference methods (25).

In another study, Chen et al. explored the impact of teaching in a conceptual mapping method to improve students' critical thinking, which concluded that the group trained in conceptual mapping method significantly improved the critical thinking (26). In the same way, Lee et al. confirmed the results of the present study in a conceptual map discussion (27). In a research using conceptual maps 


\begin{tabular}{|c|c|c|c|c|c|}
\hline Variable & Flipped Classroom ${ }^{a}$ & Conceptual Map ${ }^{\text {a }}$ & No. & $\mathbf{t}$ & PValue $^{\mathrm{b}}$ \\
\hline \multicolumn{6}{|l|}{$\begin{array}{l}\text { Components of deliberate } \\
\text { practice }\end{array}$} \\
\hline Planning & $7.29 \pm 7.2$ & $83.1 \pm 10.2$ & 60 & 5.42 & $0.001^{\mathrm{a}}$ \\
\hline Concentration/dedication & $63.14 \pm 5.2$ & $76.81 \pm 6.2$ & 60 & 1.75 & 0.084 \\
\hline Repetition/revision & $16.42 \pm 5.2$ & $66.02 \pm 6.2$ & 60 & 6.2 & 0.012 \\
\hline Study style/self-reflective & $23.93 \pm 7.4$ & $56.43 \pm 10.3$ & 60 & 3.03 & $0.004^{\mathrm{a}}$ \\
\hline Deliberate practice & $73.06 \pm 25.7$ & $83.96 \pm 34.5$ & 60 & 4.46 & $0.001^{\mathrm{a}}$ \\
\hline
\end{tabular}

in foreign language classes as a tool to understand the content of the curriculum and to achieve meaningful learning, Moreira concluded that the conceptual map to design the text was effective in learning. Kalhor and Mehran, in Iran, found that conceptual map strategy has a positive effect on academic achievement and meaningful learning, reading, and comprehension of learners in English (28). The results of the above studies confirm the results of this study.

By contrast, in a quasi-experimental study by Samawi in 2006 with the aim of studying the effect of conceptual mapping on critical thinking skills and its tendency toward third and fourth year nursing students, conceptual mapping did not improve the critical thinking level in students. Of course, according to the author, the great limitation of this study was the small sample size (29).

Studies have had different outcomes regarding the impact of the flipped classroom. In their study, Moffett and Mill concluded that the students' interest in the flipped classroom was higher than the traditional one (30). Young et al. in his study showed that students have higher performance after teaching retroactively (31). The results of this study are consistent with the results of these studies. These positive outcomes in the flipped classroom may be due to the creation of a cooperative spirit, division of labor, student and teacher interaction, and the students' pertinent encounter with the content presented. The results of Whillier and Lystad's study, which aimed to determine the effect of traditional teaching and flipped classroom on the students' score, showed no significant difference between the two methods (32).

Jensen et al. showed that flipped and non-flipped teaching equally affect students' satisfaction (33). Overmyer compared flipped classroom teaching with traditional teaching method and concluded that there was no significant difference between the two methods (34).

The results of this study showed that both conceptual map and flipped classroom had a positive impact on the deliberate practice study approach. However, by comparing the total difference mean in the two methods, effect of the conceptual map was higher than the flipped classroom. By reviewing the research and searching in scientific databases, a similar study was not found on the comparison of these two teaching methods mentioned. It seems that one of the reasons for teaching a more effective teaching method in relation to the flipped classroom in this study was the difference in designing of conceptual map by students.

In the same way, Wenders (1990) believes that the main educational benefit of a conceptual map is allocated to the constructor not the person who receives it (35). Results of the Markow and lonning study are in line with this belief (36). On the other hand, due to the influence of active and participatory learning theory, the integration of conceptual mapping method with participatory learning was considered by researchers. For this reason, in this research, our students trained a conceptual map in a group method. The results of the study by Stoyanova and Kommers showed that a collaborative conceptual map provoked greater participation and led to representational concepts (37).

Therefore, it can be said that conceptual maps provided by the students themselves are very useful tools for identifying the level of learning and the deficiencies of learners. The teacher, to a certain extent, can determine the level of understanding of the learner due to the correct and incorrect communication in these maps or the lack of communication between the concepts. One of the other causes of the impact of the conceptual map approach on the flipped classroom can be the inactivity of some learners in the presentation of the content presented before solving the classroom assignments in the flipped class. This difference can also point to the differences in learning styles in the use of flipped virtual classes so that some learners may not be able to communicate effectively with e-learning methods. 


\subsection{Conclusions}

The results of this study confirmed that the two new educational methods of conceptual map based on group participation and e-learning flipped classroom method are effective on the deliberate practice study approach, which had the most effect in planning in both methods. Considering that nursing students of the operating room and anesthesiology, as one of the most important members of the health and treatment team, should provide patients and other clients with services; they must have meaningful and sustainable learning as well as the use of critical thinking skills and problem-solving. Providing excellent services to patients is very promising. To develop such forces, conceptual maps and flipped classrooms can be used as active teaching methods in which students themselves are active in information processing.

The limitations of this study include a small number of meetings to present the content. The reason for this was the requirement for the teacher to complete the curriculum in accordance with the educational rules. Thus in these two ways, we could not teach all the titles because of the time limitation. Given the limitations and the results mentioned, it can be suggested that these two new educational methods may be used and compared in different courses and disciplines of the medical sciences in order to enhance the generalizability of this method. In addition, if possible, the samples of two teaching methods are selected from two different environments in order to minimize the impact of the neighborhood of the groups.

\section{Acknowledgments}

The researchers are grateful to the members of research council of the School of Nursing and Midwifery in Saveh University of Medical Sciences, all the students of the operating room, and anesthesiology technology as well as the training experts who helped us in this study.

\section{Footnotes}

Authors' Contribution: Study concept and design: Amin Haghgoo; acquisition of data: Amin Haghgoo, Mohadese Bolhasani, Ghazal Afsheh and Behnam Jafari; analysis and interpretation of data: Mahmood Karimy and Amin Haghgoo; drafting of the manuscript: Amin Haghgoo and Meysam Rahmani Katigari; critical revision of the manuscript for important intellectual content: Meysam Rahmani Katigari and Mahmood Karimy; statistical analysis: Mahmood Karimy and Meysam Rahmani Katigari; administrative, technical, and material support: Meysam
Rahmani Katigari and Amin Haghgoo; study supervision: Amin Haghgoo.

Conflict of Interests: Authors declare that there is no conflict of interest in this study.

Ethical Approval: All procedures performed in studies involving humans were in accordance with the ethical standards of the institution or practice at Saveh University of Medical Sciences with ethical approval code of IR.SAVEHUMS.REC1396,24.

Funding/Support: This study was funded by Saveh University of Medical Sciences.

Patient Consent: Informed consent was obtained from all participants included in this study.

\section{References}

1. BrockbankA, McGill I. Facilitating reflective learning in highereducation. McGraw-Hill Education (UK); 2007.

2. Biggs JB. Teaching for quality learning at university: What the student does. Open University Press; 2003.

3. Kolb AY, Kolb DA. Learning styles and learning spaces: Enhancing experiential learning in higher education. Acad Manage Learn Educ. 2005;4(2):193-212. doi: 10.5465/amle.2005.17268566.

4. Raines DA. CAN-Care: An innovative model of practice-based learning. Int J Nurs Educ Scholarsh. 2006;3:Article 20. doi: 10.2202/1548923X.1304. [PubMed: 17049040].

5. Shakurnia A, Alijani H, Najjar S, Elhampour H. [Correlation between educational satisfaction and approaches to study and academic performance a study of nursing and midwifery students]. Iran JMed Educ. 2014;14(2):101-9. Persian.

6. Ericsson KA, Krampe RT, Tesch-Römer C. The role of deliberate practice in the acquisition of expert performance. Psycholog Rev. 1993;100(3):363. doi: 10.1037/0033-295X.100.3.363.

7. Moulaert V, Verwijnen MG, Rikers R, Scherpbier AJ. The effects of deliberate practice in undergraduate medical education. Med Educ. 2004;38(10):1044-52. doi: 10.1111/j.1365-2929.2004.01954.x. [PubMed: 15461649].

8. Ericsson KA, Whyte J, Ward P. Expert performance in nursing: reviewing research on expertise in nursing within the framework of the expert-performance approach. ANS Adv Nurs Sci. 2007;30(1):E58-71. doi: 10.1097/00012272-200701000-00014. [PubMed: 17299276].

9. Hasheesh MA, Al-Mostafa O, Obeidat H. Traditional versus nontraditional methods of teaching: The impact on nursing teaching effectiveness and student's achievements at nursing colleges. An Najah Univ J Res. 2011;25(1):255-75.

10. Zahbyon L, Ahmadi GR. Creative thinking and its" relation to students 'academic achievement. Curriculum Planning Know Res Educ Sci. 2009;23(21):61-78.

11. Rahmani A, Mohajjel Aghdam A, Fathi Azar E, Abdullahzadeh F. [Comparing the effects of concept mapping and integration method on nursing students' learning in nursing process course in Tabriz University of Medical Sciences]. Iran J Med Educ. 2007;7(1):41-9. Persian.

12. Race P.The lecturer's toolkit: A practical guide to assessment, learning and teaching. London: Routledge; 2014. 300 p. doi: 10.4324/9781315767277.

13. Tan C, Yue WG, Fu Y. Effectiveness of flipped classrooms in nursing education: Systematic review and meta-analysis. Chinese Nursing Research. 2017;4(4):192-200. doi:10.1016/j.cnre.2017.10.006.

14. Rahman AA, Aris B, Mohamed H, Zaid NM. The influences of flipped classroom: A meta analysis. 2014 IEEE 6th Conference on Engineering Education (ICEED). IEEE; 2014. p. 24-8. 
15. Gomes AP, Dias-Coelho UC, Cavalheiro PO, Siqueira-Batista R. The role of concept maps in the medical education. Rev Bras Educ Med. 2011;35(2):275-82. doi: 10.1590/S0100-55022011000200018.

16. Mitchell DL, Bennett MJ, Manfrin-Ledet L. Spiritual development of nursing students: Developing competence to provide spiritual care to patients at the end of life. J Nurs Educ. 2006;45(9):365-70. [PubMed: 17002083].

17. McLaughlin JE, Roth MT, Glatt DM, Gharkholonarehe N, Davidson CA, Griffin LM, et al. The flipped classroom: A course redesign to foster learning and engagement in a health professions school. Acad Med. 2014;89(2):236-43. doi: 10.1097/ACM.0000000000000086. [PubMed: 24270916].

18. Sharples M, Adams A, Ferguson R, Mark G, McAndrew P, Rienties B, et al. Innovating pedagogy 2014: Exploring new forms of teaching, learning and assessment, to guide educators and policy makers. The Open University; 2014.

19. Bishop JL, Verleger MA. The flipped classroom: A survey of the research. ASEE National Conference Proceedings. Atlanta, GA. 2013. p. 1-18.

20. Dalmolin LCD, Nassar SM, Bastos RC, Mateus GP. A concept map extractor tool for teaching and learning. 2009 Ninth IEEE International Conference on Advanced Learning Technologies. IEEE; 2009. p. 18-20.

21. Masoumy M, Ebadi A, Daneshmandi M, Raisifar A. Concept mapping; modern teaching strategy in nursing education. Educt Strategies $J$. 2011;4(1):47-51.

22. Aein F, Frouzandeh N. [Investigating efficacy of concept mapping in student's learning of nursing process of pediatric patients]. J Shahrekord Uuniv Med Sci. 2012;14(2). Persian.

23. Sadeghi-Gandomani HR, Delaram M, Naseri-Brugeni N. [Comparison of concept mapping and conventional teaching methods on creativity of nursing students]. J Med Educ Dev. 2014;9(3):48-57. Persian.

24. Nili MR, Abdi H. The relationship of study approach with deliberative practice, course satisfaction and academic achievement among Isfahan University Of Medical Sciences nursing students during the 20132014 academic year. J Nurs Educ. 2016;5(2 (16)).

25. Kaddoura M, Van-Dyke O, Yang Q. Impact of a concept map teaching approach on nursing students' critical thinking skills. Nurs Health Sci. 2016;18(3):350-4. doi: 10.1111/nhs.12277. [PubMed: 26891960].

26. Chen SL, Liang T, Lee ML, Liao IC. Effects of concept map teaching on students' critical thinking and approach to learning and studying. J Nurs Educ. 2011;50(8):466-9. doi: 10.3928/01484834-20110415-06. [PubMed: 21524017].

27. Lee W, Chiang CH, Liao IC, Lee ML, Chen SL, Liang T. The longitudinal ef- fect of concept map teaching on critical thinking of nursing students. Nurse Educ Today. 2013;33(10):1219-23. doi: 10.1016/j.nedt.2012.06.010. [PubMed: 22795871].

28. Kalhor M, Mehran G. The impact of concept mapping strategy on academic achievement and meaningful learning of english reading comprehension in students. J Nurs Educ. 2017;6(1). doi: 10.21859/jne06015.

29. Boyadjian-Samawi Z. The effect of concept mapping on critical thinking skills and dispositions of junior and senior baccalaureate nursing students. Proceedings of the 2nd International Conference on Concept Mapping. San Jose, Costa Rica: University of Costa Rica. 2006.

30. Moffett J, Mill AC. Evaluation of the flipped classroom approach in a veterinary professional skills course. Adv Med Educ Pract. 2014;5:41525. doi: 10.2147/AMEP.S70160. [PubMed: 25419164]. [PubMed Central: PMC4235505].

31. Young TP, Bailey CJ, Guptill M, Thorp AW, Thomas TL. The flipped classroom: A modality for mixed asynchronous and synchronous learning in a residency program. West J Emerg Med. 2014;15(7):938-44. doi 10.5811/westjem.2014.10.23515. [PubMed: 25493157]. [PubMed Central: PMC4251258].

32. Whillier S, Lystad RP. No differences in grades or level of satisfaction in a flipped classroom for neuroanatomy. J Chiropr Educ 2015;29(2):127-33. doi: 10.7899/JCE-14-28. [PubMed: 25902472]. [PubMed Central: PMC4582610].

33. Jensen JL, Kummer TA, Godoy PM. Improvements from a flipped classroom may simply be the fruits of active learning. CBE Life Sci Educ. 2015;14(1):ar5. doi: 10.1187/cbe.14-08-0129. [PubMed: 25699543]. [PubMed Central: PMC4353080].

34. Overmyer GR. The flipped classroom model for college algebra: Effects on student achievement [dissertation]. Fort Collins, Colorad: Colorado State University; 2014.

35. Saeedi A, Saif AA, Asadzadeh H, Qavam SE. Comparing effectiveness of methods of presentation and providing concept maps on reading comprehension. Eur J Exp Biology. 2013;3(2):545-50.

36. Markow PG, Lonning RA. Usefulness of concept maps in college chemistry laboratories: Students' perceptions and effects on achievement. Official J Nation Assoc Res Sci Teach. 1998;35(9):1015-29. doi: 10.1002/(SICI)1098-2736(199811)35:9<1015::AID-TEA4>3.0.CO;2-G.

37. Stoyanova N, Kommers P. Concept mapping as a medium of shared cognition in computer-supported collaborative problem solving. J Interactive Learn Res. 2002;13(1):111-33. 